\title{
Corpo-escrita na esquizofrenia
}

\author{
Marina Bialer*
}

Este artigo aborda a importância do trabalho de escrita na esquizofrenia. Toma-se como ponto de partida a formulação lacaniana sobre o esquizofrênico como aquele que não tem as funções dos órgãos do seu corpo dadas pelos discursos estabelecidos. A hipótese de que o trabalho sobre a letra pode permitir o tratamento do gozo debordante na esquizofrenia é analisada pelo estudo da obra do escritor esquizofrênico Robert Walser, a qual evidencia a viabilidade da construção de um corpo pela escrita na esquizofrenia.

Palavras-chave: Esquizofrenia, gozo, corpo, escrita

* Pós-doutoranda na Faculdade de Educação da Universidade de São Paulo - FEUSP (São Paulo, SP, Br) e pesquisadora do Laboratório de Estudos e Pesquisas Psicanalíticas e Educacionais sobre a Infância - LEPSI da Universidade de São Paulo (São Paulo, SP, Br). 
Este artigo toma como ponto de partida a formulação lacaniana sobre o esquizofrênico como aquele que não tem as funções dos órgãos do seu corpo dadas pelos discursos sociais estabelecidos. O investimento sobre a materialidade da letra é desenvolvido como uma importante via de autotratamento na esquizofrenia, pela localização do excesso gozoso na materialidade da letra. A letra na sua dimensão real pode permitir a ancoragem de bordas, tecendo um litoral construído pelo significante e pelo gozo, peculiares a cada sujeito.

$\mathrm{O}$ esquizofrênico se depara com o seu corpo, não como uma ilusória unidade, mas como o real, disperso. Sem poder recorrer aos discursos sociais que etiquetam e nomeiam esta desarticulação, a escrita pode permitir um trabalho de crochetagem de uma linguagem no corpo, em uma tessitura de gozo e de alíngua no corpo.

Proponho seguirmos os passos do escritor Robert Walser que, tendo sido diagnosticado esquizofrênico, passou grande parte da sua vida internado em um hospital psiquiátrico. O estilo walseriano de escrever, fragmentando e quebrando seus textos, é considerado por Lacadée (2010) seu modo de construir um romance do real, uma construção que dá consistência aos seus vários fragmentos dispersos.

Em Walser, há um trabalho incessante com todos os discursos da época, sem se fixar em nenhum deles, ou melhor, sem se deixar fixar por nenhum. Nas mãos de Walser, os discursos são explorados a tal ponto que criam uma subversão de cada um dos gêneros literários em relação às normas preestabelecidas. Muitos de seus romances se tornam extremamente confusos, sem coesão, desencadeando no leitor uma movimentação contínua, em todas as direções. Há uma liberdade de movimento tanto no escrito quanto no leitor. Há sempre indicações em diferentes direções, originando uma estrutura labiríntica do texto, cujo único objetivo é a manutenção do próprio movimento.

Walser habita o labirinto: este é o lugar da sua existência, ocupando uma posição marginal em relação aos discursos sociais. Seu lugar na marginalidade dos discursos the dá toda liberdade de movimento. Na posição marginal da autoria de Walser, o leitor também é colocado em movimento, em um texto pautado na confusão permanente, na presença de indicações de todos os sentidos possíveis, da fixação definitiva em nada.

Algumas estratégias produtivas do estilo labiríntico, mais marcantes nos últimos escritos de Walser, são assinaladas com precisão por Utz (2001). A não 


\section{ARTIGOS}

linearidade na narração é originada pela introdução de interrupções abruptas do texto: a introdução de autorreflexões dos eu narrativos que parecem, ao primeiro olhar, intervir para esclarecer uma situação, mas que, na verdade, tem como consequência gerar ainda mais confusão ao produzir um corte narrativo, tornando ainda menos coerente a estrutura narrativa do texto. Tais interrupções da narrativa, para comentar o próprio processo narrativo, são destacadas por Pelletier (2008) como estratégias de desconstrução de histórias que produzem a ruptura de toda linearidade e coerência.

Há também a presença de "placas de sinalização" (Utz, 2001, p. 411) que aparecem no texto, mas que não fornecem efetivamente indicações definitivas, ao contrário, indicam todos os sentidos, produzindo ainda mais movimento no leitor, deixando-o ainda mais confuso. A produção de sentido único não é somente evitada, mas impossibilitada. Há também a presença marcante de repetições que travam o texto, deixando o leitor com a sensação de encontrar sempre a mesma coisa sem, no entanto, conseguir se fixar face a tantas repetições.

Estas "pegadinhas" narrativas são parte estruturante da narrativa walseriana, estratégias estruturais criadoras da confusão e do movimento que estruturam sua obra. Mas tais estruturas também produzem para o leitor uma abertura incessante, que constrói uma escrita estruturalmente paradoxal na qual as contradições não são resolvidas, mas coexistem; vários caminhos persistem lado a lado, e vários percursos do leitor são viáveis. Vale a pena ressaltar que tais "pegadinhas" são marcantes tanto no leitor quanto no narrador e nos personagens. Estão todos "desbussolados". Não há a omnisciência de um Outro que tudo sabe, que tem o saber do bom caminho a ser seguido. O que prevalece é um movimento sem fim, quase circular do texto, que envolve todos em repetições, reflexões e contradições que nunca são respondidas.

A impossibilidade da orientação linear nos textos walserianos também é estimulada pela abertura sem fim de possibilidades e pela formulação dos caminhos não escolhidos, desembocando em textos sem um fío condutor. Há uma dispersão de possibilidades e de caminhos que produz o movimento tanto do narrador e dos personagens quanto do leitor. Há também uma dispersão temática. Os temas do texto walseriano são múltiplos e se dissociam no transcorrer de um mesmo texto.

Além disso, há uma multiplicidade de identidades possíveis para os personagens de Walser, caracterizando uma identificação móvel, camaleônica, visto que os personagens estão sempre mudando de lugar narrativo, em uma constante dispersão da identidade. Leitor, narrador, personagem: todos em movimento pela letra de Walser. A presença de personagens que se dissociam evita a fixação definitiva: não há uma identificação imutável do eu narrativo, há, sim, uma dissociação dos personagens, do narrador, da temática textual e a cada virar de página há um novo sujeito da narração.

Os personagens walserianos são escolhidos no discurso da época, mas Walser transforma o papel que lhes é atribuído pela sociedade. Assim, por exemplo, um 
garçom, uma empregada, que teriam um laço supostamente de servir ao outro, podem imitar os mesmos rituais de aparente servidão, ao realizar uma "subversão do poder" (Utz, 2001, p. 30), através de um riso secreto, um prazer em servir, resistindo à autoridade, desvelando tais relações de força na coexistência entre os papéis do forte e do fraco. Segundo Pelletier (2008), há uma oscilação nunca resolvida de forma conciliatória nos personagens walserianos entre a afirmação da singularidade individual e uma submissão total, desembocando em soluções originais de ordem paradoxal.

A posição marginal aos discursos da época permite a Walser de um lado a sua permeabilidade à sua alíngua, e de outro lado a sua crítica pertinente aos discursos sociais. A utilização de alíngua, o trabalho sobre a sonoridade contribui à construção do movimento do tipo labiríntico que escapa, subverte os discursos e impede a fixação, pela introdução de todas estas estratégias cuja consequência estrutural é a produção de movimento. Os personagens heróis na obra walseriana são heróis vagabundos, livres, escapando de identificações aos heróis da época. Walser escapa desta identificação, evitando ser preso pelo discurso social prevalente e escapando dos ideais sociais.

$\mathrm{Na}$ relação leitor-narrador na obra de Walser, Utz (2001) ressalta também a relevância do espaço da oralidade - da língua oral pela qual se instauram os diálogos e da prevalência de alíngua produtora do espaço do transitar pelos discursos. A importância da escuta de alíngua de Walser pode ser evidenciada na importância do encadeamento sonoro dos textos, na versão original em alemão. Há um privilégio da sonoridade de alíngua, um prazer no manejo da sonoridade dos dialetos alemães que produz vocábulos inesperados, surpresas. Graf destaca um contraste entre palavras repetitivas e neologismos abruptos, inesperados, produzidos a partir da maleabilidade do léxico alemão, frutos da permeabilidade de Walser para escutar as nuances dos vários dialetos da língua alemã.

A escuta das possibilidades linguísticas originada nestas sonoridades está implicada na liberdade de movimentos e na liberdade subversiva dos gêneros literários em Walser. Tal desenvoltura permite escutar os discursos de sua época de um modo original, podendo detectar semblantes - os significantes mestres dos discursos sociais - e tendo a possibilidade de se apropriar de um discurso próprio, walseriano, de um modo totalmente singular. A crítica aos discursos sociais da época tem em Walser uma importante contribuição, posto que em seu tom irônico, ele denuncia a não existência de um Outro que sabe tudo.

A posição de marginalidade de Walser, em relação aos discursos, está na base da liberdade e originalidade. O escrever de Walser é caracterizado por Lacadée (2010) como seu método para ligar o eco da sua voz, de sua alíngua, ao seu corpo. A sensibilidade de Walser à ressonância de sua alíngua, sua capacidade de ressonar a sonoridade dos significantes e de ecoar a sonoridade da língua alemã, encontra uma solução autoterapêutica no seu estilo labiríntico de escrita, que produz uma fixação do gozo neste movimento incessante. 


\section{ARTIGOS}

Outra invenção autoterapêutica de Walser é a realização sistemática de caminhadas, que Lacadée (2010) formula como uma necessidade existencial de ligar a caminhada à escritura, bordando uma articulação entre seu corpo e as palavras que ele escuta da sua alíngua. A alternância entre o caminhar e o parar dá o ritmo para Walser poder escutar e ressonar sua alíngua. Lacadée traça um paralelo entre o ato de caminhar e o ato de escrever posto que Walser tinha um movimento contínuo, a esmo na língua, e um movimento contínuo, caminhando na neve. O tempo de parada da caminhada propiciava a Walser um ponto de corte no fluxo contínuo da escuta da alíngua, ponto que permite a imbricação da escrita à vida, uma ligação de alíngua com o corpo e com a vida.

O objetivo existencial das caminhadas de Walser não era o de chegar a um local específico, mas a produção do movimento, correlativa à criação do seu tempo de escuta, e do seu lugar de existência: o labirinto da sua escrita. As caminhadas eram uma importante estratégia autoterapêutica, sendo que mesmo Walser (1987) reconhecia que sem elas, ele estaria morto, incapaz de escrever.

Walser opõe o estado de empobrecimento quando fechado em si mesmo ao estado em que ele se encontra nas caminhadas, em contato com o mundo e recebendo da sua alíngua muitas ideias, plenas de vitalidade. Vale a pena sublinhar a importância explicitada por Walser do momento da parada da caminhada, para não ser submergido pela força pulsante de todas as ideias que escuta, de todos os fenômenos estranhos que lhe tocam, podendo, a partir da parada, não somente escutar algo original, singular, mas também acolher tais fenômenos e estabelecer um laço prazeroso que ele descreve de "amizade" (p. 81) com tais fenômenos estranhos. O escritor salienta que de tais fenômenos estranhos, singulares, ele pode fazer corpos dotados de substância, o que me parece se concretizar na sua obra escrita.

A escrita de Walser afeta o seu corpo. Nas caminhadas de Walser se escreve e se inscreve algo de alíngua. Trata-se de uma obra enraizada neste corpo em movimento, este corpo que caminha alicerçando um escrever que afeta o corpo, um escrever com o corpo. A construção do corpo-escrita, de uma escrita enraizada na escuta de alíngua, de uma escrita que inscreve no corpo alíngua, permite a Walser uma solução existencial.

Nas paradas ao caminhar, há a construção de uma temporalidade, que pode ser formulada como a construção de um lugar de existência que remeto à formulação de Oury (1989) sobre a importância do lugar da inscrição de um lugar existencial na clínica da esquizofrênia.

Há um momento de ruptura na existência de Walser, designada a crise da pluma por Lacadée (2010). A crise da escrita é descrita como uma falha da sua mão em um momento de sideração, de impossibilidade de escrever, no período de uma crise ao mesmo tempo física e mental, da qual Walser só conseguiu se recuperar por uma transformação, pelo desdobramento do seu escrever em duas etapas distintas. 
O escritor atribuirá a sua recuperação ao seu novo procedimento que implicava primeira etapa, do escrever a lápis, e a segunda etapa, do recopiar, o que, segundo ele relata, embora fosse uma tarefa burocrática, permitiu-lhe reaprender a escrever e poder ter, novamente, prazer neste processo. Ele descreve a importância existencial de escrever utilizando os lápis, com todo cuidado, em um trabalho que produzia um ritmo mais lento, calmo, construindo um "método de trabalho" (Walser, 2004, p. 36) com poder terapêutico, curativo da sua crise, que ele descreve como uma dissolução da sua escrita na sua falha da mão.

O desdobramento do processo de escrita foi o autotratamento inventado por Walser que permitiu uma localização deste gozo, debordante na crise, na materialidade dos seus escritos. O processo de minimização da letra em um investimento no trabalho manual do escrever, assim como o desdobramento do processo em duas etapas, são descritos como autoterapêuticos pelo próprio Walser. Assim sendo, podemos formular que tais estratégias permitiram à Walser localizar o gozo debordante, ilimitado.

A materialidade de letra pode acolher o gozo. E o trabalho walseriano evidencia a importância do investimento na letra, permitindo-lhe recuperar-se da perda da sua consistência, da vivência de perda da sua mão, da perda dos pedaços do seu corpo, e da sua posterior recuperação pela letra.

O procedimento de duplificação do processo de escrever é designado por Morlang (2004) de sistema binário, sendo enfatizado por Utz (2003) o aspecto de desdobramento deste sistema em dois tempos necessários, vitais. Ao observamos a descrição de Walser deste processo, é nítida a existência de um espaço entre os dois tempos, um lugar existencial, um vazio criado pelo processo binário de escrita. Podemos formular que tal inscrição binária dos traços nas letras é a criação do lugar de um vazio, do tempo de pausa, do tempo de parada, similar àquele criado nas caminhadas. Tal espaço entre as duas etapas estaria, assim, na base de um tempo inventado no qual seria possível bordar novamente a alíngua ao corpo pelo processo de escrever.

A letra, a dimensão real da letra pode cavar um buraco, originando um vazio estruturante para o ser humano. $\mathrm{O}$ trabalho sobre a letra, implica um investimento em uma dimensão que não é da cadeia significante, mas que toca à la Chose, de algo anterior ao significante, algo do real. Trata-se da possibilidade da invenção singular que cada sujeito pode fazer com o seu real. A letra pode ser uma via para uma inscrição sobre la Chose, para a transformação de um vazio mediano, não pleno, construído sobre o fundo do pleno. Oury (1989) realiza um percurso original para pensar a esquizofrenia a partir da questão do vazio. Há uma oposição estrutural entre um vazio central, criado pelo objeto(a), delimitando um íntimo em extimidade, e o vazio na esquizofrenia, não marcado, não delimitado. Uma solução esquizofrênica seria para Oury a construção possível de uma bricolagem com os pedaços de real em um objeto, ou em alguma autocriação que permita a inscrição 


\section{ARTIGOS}

equivalente a uma organização dos pedaços dispersos. A construção de uma obra de arte, a construção literária, a confecção de um objeto etc., poderiam ter esta função de fabricação de uma consistência de si mesmo, de marcações, de inscrições reais que permitiriam uma nova relação ao corpo próprio, ao tempo e ao espaço. A autocriação desta bricolagem real pode permitir a criação equivalente ao vaso que Lacan (1959-1960) utiliza para ilustrar a inscrição primordial sobre la Chose, uma marcação no real.

Trata-se de uma marca, um traçado no real que permite a inscrição inaugural, a introdução de uma descontinuidade, através de um traço de diferença. Vale a pena ressaltar que Oury situa uma condição preliminar necessária para que a construção deste objeto, arte, escrito, seja possível. É a construção de um lugar de existência, um lugar que permita o acolhimento destas partes do real e o enlaçamento das partes dispersas, um lugar para situar o que estava à deriva. Para poder criar uma descontinuidade no que era um vazio pleno, sugiro colocar em paralelo o trabalho criador de um lugar de existência, como formulado por Oury, ao trabalho de investimento sobre a materialidade da letra na esquizofrenia. Oury formula dois pontos que são essenciais para a clínica da modalidade esquizofrênica de tratamento do real e dos quais pretendo me apropriar para formular a importância da inscrição de um traço diferencial, de uma delimitação de um vazio mediano, de um lugar de existência a partir do qual é possível tecer uma construção vital, e a importância da criação deste objeto suplementar, que permita localizar o gozo excessivo, tal objeto sendo de importância vital, podendo mesmo assegurar a consistência da sua existência, assegurando uma colagem das partes do seu corpo, uma colagem das partes que antes estavam dispersas.

O investimento sobre a letra permite a Walser a localização de um gozo debordante. E tal trabalho sobre a materialidade da letra permite a criação de um vazio. Proponho que a temporalidade introduzida no texto, o tempo de pausa, cria no texto o lugar do vazio, que não está em relação a uma inércia, mas, ao contrário, ao movimento, a partir da inscrição de uma descontinuidade.

A alternância entre o movimento e a pausa na caminhada, a alternância entre o movimento da escrita em miniatura e o movimento da escrita da versão copiada, e a criação de um espaço existencial entre as duas escritas, permite a inscrição corporal de alíngua. Caminhando e escrevendo, Walser sustentou o seu corpo pela letra, pela escrita, inscrevendo alíngua no corpo, a partir da criação de um tempo para poder escutar e escrever/inscrever a alíngua.

Há toda uma atenção à materialidade, ao traçado e à pressão na escrita do fenômeno estrangeiro ao qual Walser está submetido, da ordem de um automatismo mental que se impõe. A partir do investimento sobre a letra, o trabalho de escrita pôde permitir uma tessitura de fragmentos àquele que não tem acesso ao fechamento da cadeia significante pela significação fálica. O privilégio do investimento do gozo na 
materialidade da letra no esquizofrênico pode favorecer a não fragmentação do pensamento, que poderia ser uma das consequências do não encadeamento significante.

Na obra walseriana, especialmente nos escritos em miniatura, não se trata de um endereçamento de uma mensagem a um Outro, mas de uma localização do gozo na letra. A escrita de estilo labiríntico, o aspecto enigmático de sua escrita, oferece, segundo Lacadée (2010), um abrigo para se sustentar na existência; sustento assegurado pelo ato incessante de escrever, posto que a crise da escrita equivaleria para Walser a uma desertificação da vida. Já no escrever que implica o corpo, na letra, real, origina-se alíngua impressa nos litorais do corpo, que permite a fixação do gozo na esquizofrênia. Os procedimentos autoterapêuticos de Walser cavaram um vazio como resultado do efeito real da letra, equivalendo à substração de uma rondela do estofo do real.

O trabalho sobre a letra permitiu a Walser tanto a localização do gozo na letra quanto a construção de um espaço de existência, de um vazio a partir do qual pôde ser construído um corpo de letras, podendo suplantar a posição esquizofrênica, nas margens dos discursos sociais que etiquetariam seus órgãos, por uma etiquetagem dada pela alíngua, por uma alíngua crochetada no corpo.

\section{Referências}

Bialer, M. (2012). Le corps dans l'autisme et dans la schizophrénie. (Tese de doutorado inédita). Université Paris 7 - Denis Diderot, Paris, França/Universidade de São Paulo, São Paulo, SP.

Graf, M. (2003). Note de la traductrice. In Walser, R. Le territoire du crayon. Microgrammes (pp. 378-381). Carouge-Genève: Editions Zoé.

Lacadée, P., \& Robert W. (2010). Le Promeneur Ironique. Enseignements psychanalytiques de l'écriture d'un «roman du réel». Nantes: Éditions Cécile Defaut.

Lacan, J. (2006). Le séminaire. Livre XVI. D’un Autre à l'autre. Paris: Seuil (Trabalho original publicado em 1968-1969).

Morlang, W. (2004). Magie du camouflage micrographique. In Walser, R. L'écriture miniature (pp. 13-26). Carouge-Genève: Édition Zoé.

Oury, J. (1989). Création et schizophrénie. Paris: Éditions Galilée.

Pelletier, N. (2008). Histoires de Robert Walser. In Pelletier, N., \& Dentan, M. Robert Walser: Le Rien et le provisoire (pp. 19-40). Carouge-Genéve: Éditions Zoé.

Utz, P. (2001). Robert Walser: Danser dans les marges. Genève: Éditions Zoé.

Utz, P. (2003). Mystère et singulier bonheur des microgrammes. In Walser, R. Le territoire du crayon. Microgrammes (pp. 361-377). Carouge-Genève: Editions Zoé. 


\section{ARTIGOS}

Utz, P. (2004). Avant-Propos. In Walser, R. L'écriture miniature (pp. 5-11). Carouge-Genève: Éditions Zoé.

Walser, R. (1987). La promenade. Mesnil-sur-l'Estrée: Gallimard.

Walser, R. (2003). Le territoire du crayon. Microgrammes. Carouge-Genève: Editions Zoé.

Walser, R. (2004). L'écriture miniature. Carouge-Genève: Éditions Zoé.

\section{Resumos}

(Body-writing in schizophrenia)

This article focuses on the importance of the work of writing in schizophrenia. It takes as a starting point the Lacanian formulation of the schizophrenic as someone whose organ functions are not given by any established discourse. The hypothesis to the effect that work with the letter may allow the treatment of excessive jouissance in schizophrenia, is analyzed through writings by Robert Walser, a schizophrenic, which demonstrate the feasibility of building a body through the process of writing.

Key words: Schizophrenia, jouissance, body, writing

(Corps-écriture et schizophrénie)

Cet article traite de l'importance du travail de l'écriture dans la schizophrénie. On prend comme point de départ la formulation lacanienne du schizophrène comme sujet dont les fonctions des organes corporels ne sont pas déterminées par les discours établis. L'hypothèse selon laquelle le travail sur la lettre peut permettre le traitement de la jouissance débordante de la schizophrénie est analysée par l'étude de l'œuvre de l'écrivain schizophrène Robert Walser, ce qui démontre la faisabilité de la construction d'un corps par l'écriture dans la schizophrénie.

Mots clés: Schizophrénie, jouissance, corps, écriture

(La escritura del cuerpo en la esquizofrenia)

En este artículo se analiza la importancia del trabajo de la escritura en la esquizofrenia. Toma como punto de partida la formulación lacaniana sobre el esquizofrénico como aquel que no tiene las funciones de los órganos del cuerpo dados por los discursos establecidos. La hipótesis de que el trabajo con la letra puede permitir el tratamiento del goce desbordante en la esquizofrenia es analisada por el estudio de la obra del escritor esquizofrénico Robert Walser, que demuestra la viabilidad de construir un cuerpo por medio de la escritura en la esquizofrenia.

Palabras claves: Esquizofrenia, goce, cuerpo, escritura 
(Schriftzug in der Schizophrenie)

Dieser Beitrag behandelt die Bedeutung der schriftlichen Tätigkeit in der Schizophrenie. Ausgangspunkt ist die lacanische Formulierung von Schizophrenie, dass der Schizophrene eine Person ist, deren Körperfunktionen nicht von vorbestimmten Auffassungen gesteuert werden. Die Hypothese, dass die Untersuchung des Schriftzuges die Behandlung der Lust ermöglicht, die sich durch die Schizophrenie äußert, wird in der Untersuchung der Werke des schizophrenen Schriftstellers Robert Walser analysiert. Sie zeigt die Möglichkeit, einen Körper durch die Schrift in der Schizofrenie zu erschaffen.

Schlüsselwörter: Schizofrenie, Lust, Körper, Schrift

Citação/Citation: Bialer, M. (2014, março). Corpo-escrita na esquizofrenia. Revista Latinoamericana de Psicopatologia Fundamental, 17(1), 29-38.

Editor do artigo/Editor: Manoel Tosta Berlinck

Recebido/Received: 30.1.2013/ 1.30.2013 Aceito/Accepted: 7.4.2013 / 4.7.2013

Copyright: (C) 2009 Associação Universitária de Pesquisa em Psicopatologia Fundamental/ University Association for Research in Fundamental Psychopathology. Este é um artigo de livre acesso, que permite uso irrestrito, distribuição e reprodução em qualquer meio, desde que o autor e a fonte sejam citados / This is an open-access article, which permits unrestricted use, distribution, and reproduction in any medium, provided the original authors and sources are credited.

Financiamento/Funding: A autora declara não ter sido financiada ou apoiada / The author has no support or funding to report.

Conflito de interesses/Conflict of interest: A autora declara que não há conflito de interesses / The author declares that has no conflict of interest.

\section{Marina Bialer}

Psicóloga; Psicanalista; Master em Lettres, Langues, Sciences Humaines et Sociales na Université Paris 7 - Denis Diderot (Paris, Fr); doutora em Psicologia Clínica pela Universidade de São Paulo - USP (São Paulo, SP, Br); doutora em Recherches en Psychopathologie et Psychanalyse pela Université Paris 7 - Denis Diderot. Pesquisa realizada como Membro-Doutoranda do laboratório Psychanalyse, Médecine et Société coordenado pelo Prof. Alain Vanier - CRPMS - Université Paris 7 - Denis Diderot. Artigo baseado na tese de doutorado.

Rua João Ramalho, 257/24

05008-001 São Paulo, SP, Br.

e-mail: mbialer@hotmail.com 